
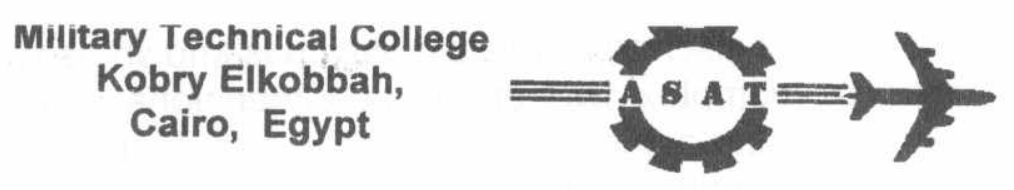

$8^{\text {th }}$ International Conference on Aerospace Sciences \& Aviation Technology

\title{
CUTTING PARAMETERS AND SURFACE CHARACTERISTICS OF WIRE EDM
}

\author{
Dr. M. ABDEL MOHSEN MAHDY*, Dr. A.M. KOHAIL**, \\ Eng. M.M. SOBEIH**
}

\begin{abstract}
Electric discharge wire cutting (EDWC), or wire EDM, is a special form of electric discharge machining that uses a small diameter wire as an electrode to cut a narrow kerf in the workpiece. The cutting action in wire EDM is achieved by thermal energy resulting from electric discharge between the electrode wire and the workpiece. Computerized numerical control is used to control the workpiece or wire motion during cutting. The special features of wire EDM make it ideal for making components for stamping dies. It is often possible to fabricate punch and die in a single cut, as well as tools and parts with intricate outlines, such as lathe form tools, extrusion dies, and flat templates, which are made easily, regardless of hardness or toughness of the workpiece material.
\end{abstract}

The wire EDM process has many parameters that affect the performance of the cutting operation, such as peak current value, pulse duration, time between sparks.. etc. The aim of the present paper is to introduce the study of the effect of the different cutting parameters on the performance of the operation. This study enables the selection of the proper wire EDM conditions leading to maximum metal removal rate with minimum surface roughness. Scanning electron microscope (SEM) and energy dispersive spectrometry (EDS) were also used to study Wire EDM subsurface layer characteristics.

\section{KEY WORDS}

Wire EDM, Cutting parameters, Surface characteristics.

\section{INTRODUCTION}

Electrical discharge machining, so called EDM, is a thermal process which is used to produce cavities or holes in an electrically conductive workpiece. The cutting tool is a copper or graphite electrode, which and the workpiece are positioned in such a way that a small gap is maintained between them. This gap is filled with a dielectric fluid to control the electrical resistance in this gap. A high D.C. voltage is then applied between the electrode and the workpiece causing a spark to occur between them, which causes erosion in both the workpiece and the electrode.

\footnotetext{
* Ain Shams Univ., Faculty of Eng., Prod. and Design Dept.

** M.T.C., Production Eng. and Management Dept.
} 
A newcomer in EDM process is the electrical discharge wire cut, which is known as wire EDM. This process is used to produce complex two and three-dimensional shapes through electrically conductive workpiece using a thin wire $(0.05$ to $0.3 \mathrm{~mm}$ diameter) as an electrode. Wire EDM was first used on a limited basis beginning in 1968, by 1975 its popularity was rapidly increased because the process capabilities were better understood by industry. [1]

In this process the wire is unwound from a spool, passing through the workpiece and driven towards the part, Fig. 1. As the wire comes close to the part (not actually touching it), a spark will occur. This spark is sufficient to generate enough heat to actually melt and evaporate a small portion of the workpiece. The evaporated material will instantaneously solidify to form small particles. After finishing the spark, electricity in the wire is removed and the flushing dielectric will remove the particles from the machining area and the worn wire goes away and the process repeats over to produce the desired component.

Workpiece material is eroded ahead of the traveling wire by spark discharge, which are identical with that in conventional EDM. There is no mechanical contact or cutting forces between the wire and the workpiece in wire EDM. The gap between the wire and the workpiece ranges from 0.025 to $0.05 \mathrm{~mm}$ [2], and is maintained constant by a computer controlled system. This gap is filled with deionized water as a dielectric fluid, this is because of its low viscosity, high cooling rate, high material removal rate, and no fire hazard. [2], [3]. Deionized water dielectric systems reuse the water by first filtering the collected water with paper filters, then water resistivity is corrected by passing through a mixed - bed deionizing cartridge.

With wire EDM technology, complicated cutouts can be made through difficult to machine metals without the need to use either high cost finishing operations or expensive formed EDM electrodes. The high degree of accuracy obtained and the fine finish cut make wire EDM particularly valuable for application involving the manufacturing of press stamping dies, extrusion dies, prototype parts, and even for fabrication of conventional EDM electrodes. Furthermore, because the operation is almost computer numerically controlled and involves relatively long cycles, it is possible for one operator to operate several wire EDM machines.

The aim of the present paper is to introduce a study of the effect of different cutting parameters on the rate of metal removal and the produced surface conditions. This investigation is useful for the selection of the proper wire EDM parameters leading to maximum rate of metal removal and good surface characteristics. Average roughness height (Ra), SEM and EDS were used to evaluate the produced surface characteristics.

\section{PERFORMANCE MEASUREMENT}

Performance measures for traditional EDM machining which have been considered by others [4] include metal removal rate, surface finish, overcut, relative electrode wear, tool wear rate and taper. For Wire EDM metal removal rate, surface finish and overcut are the most important considerations, [4]. Earlier work has been done by Matsuda et al [5] using work length and angle accuracy as measures of performance. In the present work metal removal rate and average roughness height 
(Ra) were taken as a measure of wire EDM performance. As well, SEM and EDS analysis were also used to study surface characteristics.

The metal removal rate was calculated by dividing the volume of kerf by the machining time that is displayed on the control unit of the machine. The average roughness height, $R_{a}$ was measured using Surftest 402 (manufactured by Mitutoyo - Japan). The surface produced by wire EDM was Analyzed using a scanning electron microscope (SEM) type Remmi $202 \mathrm{M}$, which provides magnification from 10 to $400,000 \times$ with resolution $10 \mathrm{~A}^{\circ}$.

\section{EXPERIMENTAL WORK}

The wire EDM process has several parameters that affect the measures of performance. Based on experience and the literature survey the following parameters will be studied: -

- Pulse Duration (ON Time)

- Time Between Sparks (OFF Time)

- Peak current (IP)

- Wire Speed (S)
- Wire Tension $(\mathrm{T})$

- Wire Type

- Flushing Flow Rate (f)

The other parameters are held constant as shown in the following table: -

\begin{tabular}{|c|c|c|c|c|c|c|c|}
\hline $\begin{array}{c}\text { Open } \\
\text { Gap } \\
\text { Voltage }\end{array}$ & $\begin{array}{c}\text { Workpiece } \\
\text { Thickness }\end{array}$ & $\begin{array}{c}\text { Workpiece } \\
\text { Material }\end{array}$ & $\begin{array}{c}\text { Length } \\
\text { of Cut }\end{array}$ & $\begin{array}{c}\text { Angle } \\
\text { of Cut }\end{array}$ & $\begin{array}{c}\text { Dielectric } \\
\text { Resistance }\end{array}$ & $\begin{array}{c}\text { Wire } \\
\text { Diameter }\end{array}$ & $\begin{array}{c}\text { Wire } \\
\text { Offset }\end{array}$ \\
\hline $\begin{array}{c}120 \\
\text { Volt, } \\
\text { Set no. } \\
(03)\end{array}$ & $20 \mathrm{~mm}$ & $\begin{array}{c}\text { Cold work } \\
\text { tool steel } \\
\text { K100 }\end{array}$ & $10 \mathrm{~mm}$ & Vertical & $\begin{array}{c}5^{*} 10^{4} \\
\text { Ohm* } \mathrm{Cm}\end{array}$ & $0.25 \mathrm{~mm}$ & $\begin{array}{c}180 \\
\mu \mathrm{m}\end{array}$ \\
\hline
\end{tabular}

The used workpiece material is cold work tool steel. Fig. 2 shows the EDS analysis of the workpiece surface before cutting with wire EDM as well as its chemical analysis. The machined surfaces were produced on an A320D wire EDM, CNC machine with EX21 control unit (manufactured by Sodick - Japan). This control has the following parameters:

"ON" stands for "ON time". This parameter controls the time duration of EDM sparks, Fig. 3 , or the time that power is applied to the wire. The used values of ON time were 6 , $30,60,150$, and $350(\mu \mathrm{s})$, (which are adjusted on the machine as $03,07,11,15$, and 19) respectively.

"OFF" stands for "OFF time". This parameter controls the time between sparks. Fig. 4, Usually ON time and OFF time are considered together for their effects. The used values of OFF time were $15,20,30,50$, and 250 ( $\mu \mathrm{s}$ ), (which are adjusted on the machine as $10,15,20,25$, and 31 ) respectively.

"IP" stands for peak current. IP controls the amount of current intensity that is applied to the wire. IP is one of the factors that adds power to the wire. The used values of this parameter are 200, 240,300,320, and 350 (Amp.), (which are adjusted on the machine as $10,12,15,16$, and 17 ) respectively. 
Voltage is a function of workpiece thickness. The thicker the workpiece, the greater the voltage that can be used without fear of wire breakage. This is because a thick part allows the power in the wire to be dispersed over a greater area. [6]. This parameter ranges from 60-120 volt. The wire offset $(H)$ is the distance between the wire center position and the produced surface. This means that wire offset is equal to the wire radius plus the spark gap.

\section{RESULTS AND DISCUSSION}

\section{Structure and Characteristics of the Section Produced by Wire EDM}

In EDM, material removal is principally due to a thermal phenomenon. It is known that the temperature of a discharge lies in the region of $8,000^{\circ}$ to $12,000^{\circ} \mathrm{C}[7]$. These high temperatures obviously have an effect upon the structure of the machined material. This effect is of greater or less significance according to the type of material, Fig. 5 shows the modification in structure in the metallurgical section of the used cold work tool steel which is produced by wire EDM. From the examination of this section, three superimposed layers can be detected as follows. [7]

- A layer of molten metal ejected and partially redeposited as few small adherent spheres.

- A recast metal layer usually referred to as the "white layer". This has no constant thickness and is very hard, due to the combination of high carbon and hardening effect.

- A layer in which the steel structure has been modified and has lower hardness due to annealing.

\section{Effect of ON Time}

It was found out that the increase of the ON time causes the increase of both the rate of metal removal and the average roughness height $(\mathrm{Ra})$ as shown in Fig. 6 . The increase of the rate of metal removal is due to the increase of the period during which current flows through the gap (discharge time) or the increase of time during which power is applied to the wire (pulse duration) [6]. While the increase of the average roughness height (Ra) with the increase of the rate of metal removal is due to the increase of the volurne of the evaporated metal with higher value of discharge time or ON time, which causes the increase of the layer of melted, ejected and partially redeposited material in the form of adherent coarse spheres. Fig. 7 shows the SEM microstructure of the surface produced by wire EDM to illustrate the effect of ON time, It can be noticed that higher $\mathrm{ON}$ time gives larger adherent spheres on the surface. Therefore, the used ON time for roughing is higher than that for finishing.

Fig. 8 shows the EDS analysis of the surface produced by wire EDM. Frorn EDS it was shown noticeable amounts of copper and zinc. These percentages of $\mathrm{Cu}$ and $\mathrm{Zn}$ are not normally found on the workpiece material before cutting by wire EDM Fig. 2, which means that some amount of the wire material is deposited on the workpiece surface. The increase of the ON time from 6 to $350(\mu \mathrm{s})$ causes the increase of the percentage amounts of copper and zinc by $550 \%$ and $800 \%$ respectively on the surface produced by wire EDM due to the increase of the rate of wear of wire. 


\section{Effect of OFF Time}

The OFF time parameter controls the time between discharges. During this time particles removed from the workpiece (and the wire) are flushed away from the machining area, so that increasing the OFF time leads to an increase in the time during which power is from the wire which results in a decrease of metal removal rate, Fig. 9-a. Morever the increase of OFF time causes the increase of the average roughness height (Ra) as shown in Fig. 9-b, whereas low OFF time will lead to high pulse frequency, which results in relatively low surface roughness. This is because the energy available for material removal during a given period is shared by a larger number of sparks; hence,' the corresponding crater size is reduced [1], Fig. 10.

Fig. 11 shows the SEM microstructure of the surface produced by wire EDM for different OFF times. It can be noticed that for low OFF time the surface contains finer adherent spheres which results is lower average roughness height (Ra). While Fig. 12 shows the EDS analysis of the surface produced by wire EDM for different OFF times. It was found that the increase of OFF time causes the decrease of the percentage of the copper and zinc deposited on workpiece surface. This is due to the decrease of the number of sparks and also due to the increase of the time taken for flushing of motten particles.

\section{Effect of IP}

The increase peak current (IP) increases the amount of power that is applied to the wire which leads to increasing the amount of material removed from the workpiece Fig. 13 [1]. Fig. 14 shows that the increase of IP causes the increase of the metal removal rate and the average roughness height due to the increase of the machining current.

Fig. 15 shows the SEM microstructure of the surface produced by wire EDM to illustrate the effect of IP, the higher value of IP the coarser adherent spheres on the workpiece surface. Fig. 16 shows EDS analysis for different IP values. It can be shown that the increase of IP no. from 15 to 17 causes the increase of the copper percentage from 0.9 $\%$ to $26.1 \%$ and the increase of zinc percentage from $0.9 \%$ to $4.9 \%$ respectively. The increase of the amount of copper and zinc of the wire materials deposited on the workpiece surface is due to the increase of the machining current associated with higher removal rate.

\section{Effect of Wire Type}

Fig. 17 shows the effect of the different wire types on the metal removal rate and average roughness height. The results indicated that the brass wire coated with zinc gives higher rate of metal removal than brass wire without coating Fig.17-a. As reported by Sho et al [8] the machining rate increases with the increase of zinc content in the wire, where higher zinc content allows lower breakdown voltage, thereby making short circuiting difficult. In addition, Dan Scott et al [4] stated that the increase of zinc content causes cooling due to zinc evaporation while zinc oxide coating helps to prevent short circuits.

Steel wire coated with brass gives higher rate of metal removal than using brass wire without coating where the brass coat on steel wire gives cooling by zinc evaporation while small zinc oxide coating prevents short circuit. However, brass wire only results in a thick layer of zinc oxide, which reduces rate of metal removal due to its higher resistivity. Fig. 17-b shows that the brass coated by zinc gives higher average 
roughness height than brass wire only due to the increase of rate of metal removal that results in coarse adherent spheres on the surface. The average roughness height when using brass wire is lower than that when using steel wire coated by brass. This is due to the thick zinc oxide layer on the brass wire that reduces the rate of metal removal comprared with steel wire coated by brass.

Fig. 18 shows the analysis EDS of the surface produced by wire EDM for different wire types. As shown in Fig. 19 also, the brass wire gives higher percentage of copper and zinc on the workpiece surface. While the brass coated with zinc layer gives a lower percentage of copper without any zinc percentage, where zinc coating is evaporated causing cooling only. Steel wire coated by brass gives lower percentage of copper and zinc on the produced surface than brass wire. Where the coating of brass consumed for cooling as zinc evaporation while a portion of that coating appeared on the produced surface. While brass wire worn contributed for zinc evaporation as cooling and a higher percentage of copper and zinc on the workpiece surface.

\section{Effect of Wire Speed}

Fig 20 shows that the increase of wire speed causes the increase of metal removal rate and surface roughness height. Where the decrease of wire speed causes the increase of wire wear, which cause the increase of gap and consequently the decrease of the machining current. Therefore, increase of wire speed cause small wear in wire and hence both metal removal rate and surface roughness increases.

\section{Effect of Wire Tension}

The increase of wire tension causes the increase of metal removal rate and decrease of surface roughness as shown in Fig. 21. Increasing of metal removal rate by the increase of wire tension is due to the decrease of the effective gap, which causes the increase of the machining current. While the decrease of surface roughness height by increasing wire tension is due to the decrease of area exposed to cutting.

\section{Effect of Flushing Flow rate}

Fig. 22 shows that increasing flushing flow rate will increase the metal removal rate and decreases the surface roughness. Where the existence of molten and evaporated particles in the cutting area increases the conductivity of the deionized water, which leads to weak sparking. Increasing flushing flow rate helps in removing these particles from the cutting area, which decreases the conductivity of the deionized water, and hence leads to powerful sparks and high metal removal rate. At the same time the high pressure flushing helps in removing the coarse particles resulting from cutting and prevents it from redepositing on the workpiece surface, which results in lower surface roughness. Fig.22-b

\section{CONCLUSIONS}

1- Increasing ON time and peak current as well as decreasing OFF time causes an increase of the metal removal rate, and the amount of copper and zinc redeposited on the produced surface. While increasing ON time, peak current and OFF time causes an increase of the surface roughness. 
2- Brass wire coated with zinc gives higher metal removal rate and surface roughness than brass wire only. Which a very small percentage of copper is only redeposited on the produced surface due to coating.

3- Increasing both wire speed and wire tension will increase metal removal rate and will decrease surface roughness.

4- Increasing flushing flow rate increases metal removal rate and decreases surface roughness.

\section{REFERENCES}

[1] Gary F. Benedict, Non Traditional Manufacturing Processes, Marcel Dekker, Inc. New York, 1987

[2] A.J. Lissaman, S.J. Martin, Principles of engineering Production, The English Language Book Society and Hodder \&Stoughton, London, 1982

[3] Huntress E.A., Electrical Discharge Machining, American Machinist, August, 8398, 1978.

[4] Dan Scatt, Sreedhar Boyina, K.P. Rajurkar, Analysis and Optimization of Parameter Combinations in Wire Electrical Discharge Machining, International Journal of Production Research, Vol. 29, No. 11, 2189-2207, 1991

[5] Matsuda J., Tomishige S., Tanaka K., and Yano H., Evaluation of performance of WEDM by Parameter Design, Proceeding of The International Symposium for Electrical Machining (ISEM-9) Nagoya, pp. 68-71,1989

[6] Sodick Inc, Classroom Training Manual, Part No. 9200001, Sodick Inc. Ltd. Japan, 1992

[7] G.Semon, ing., A Practical Guide to Elecro-Discharge Machining, 1975

[8] Sho, H., Orimo, T., and Fukui, M., The effect of electrode materials on the characteristics of machinability of wire electro discharge machines, Proceedings of the International symposium for Electro Machining (ISEM-9) Nagoya, PP.80-83. , 1989 


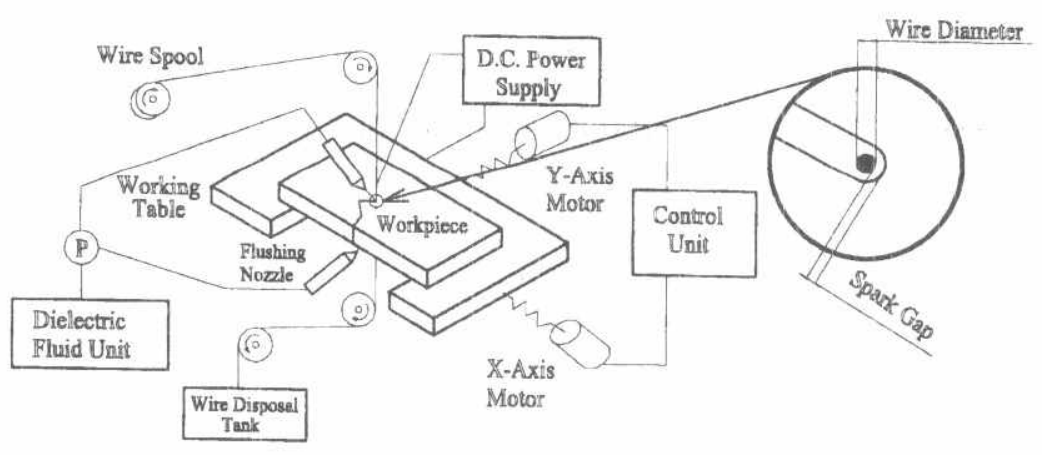

FIG.1: WIRE-EDM, CNC MACHINING WITH A WIRE ELECTRODE

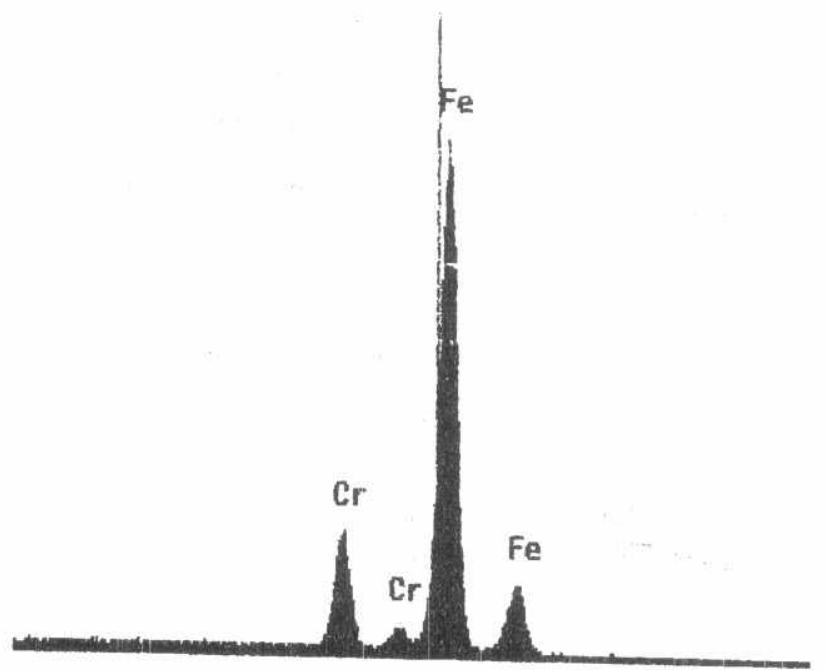

FIG. 2: ANALYSIS EDS OF THE WORKPIECE SURFACE BEFORE CUTTING BY WIRE EDM

Workpiece chemical analysis: $85.44 \% \mathrm{Fe}, 1.98 \% \mathrm{C}, 0.19 \% \mathrm{Si}, 0.32 \% \mathrm{Mn}, 11.84 \% \mathrm{Cr}$, $0.18 \% \mathrm{Ni}, 0.05 \% \mathrm{~W}$

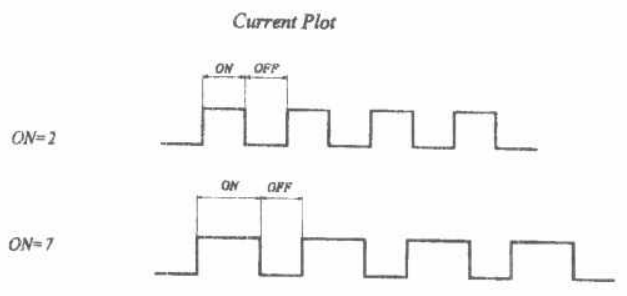

FIG. 3: CURRENT PLOT FOR DIFFERENT ON TIMES

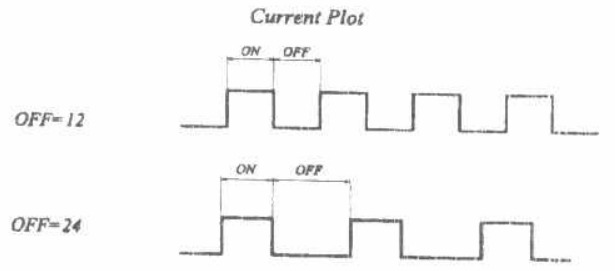

FIG. 4: CURRENT PLOT FOR DIFFERENT OFF TIMES 


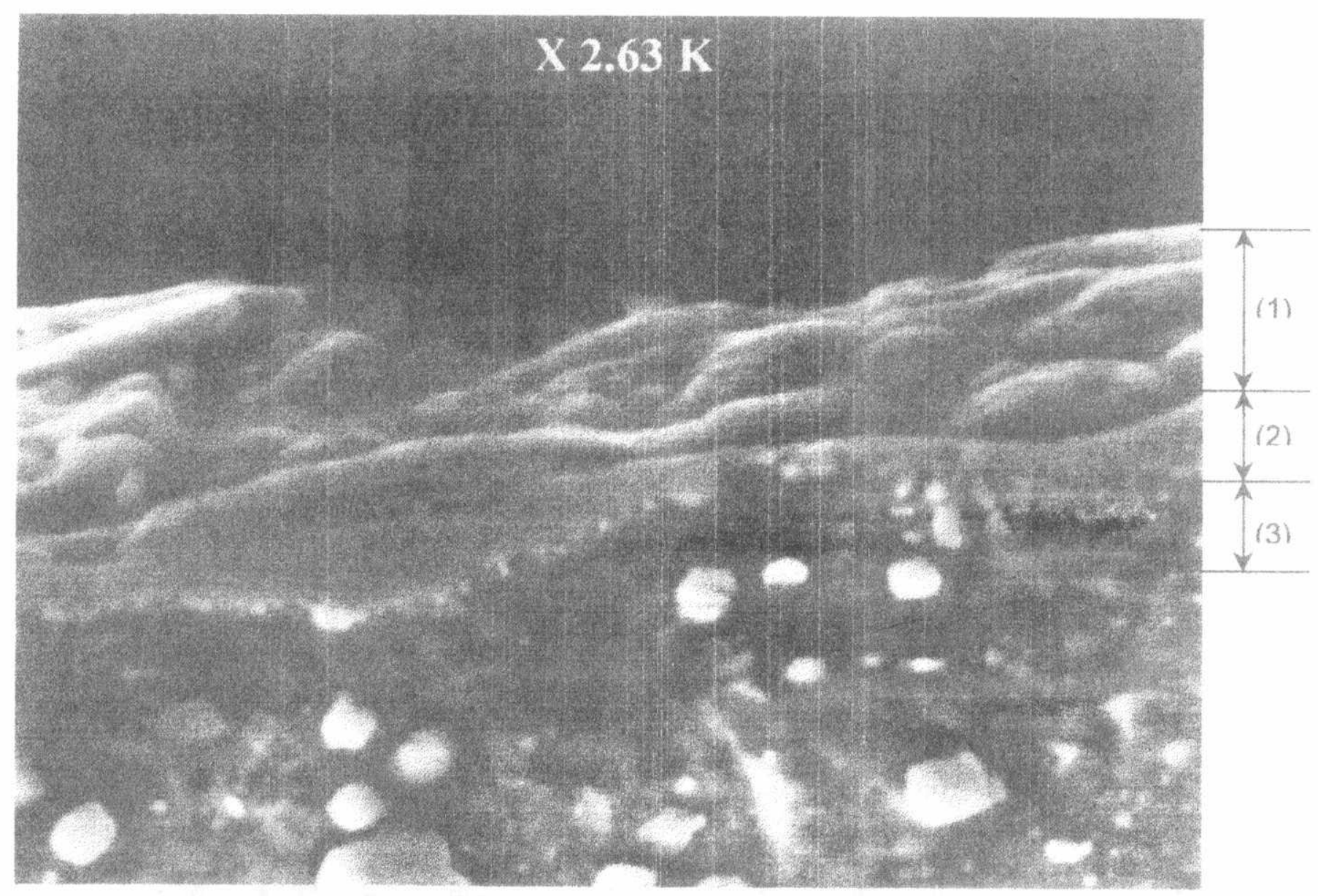

FIG. 5: THE MODIFIED LAYERS IN METALLURGICAL SECTION OF THE WORKPIECE PRODUCED BY WIRE EDM

(1) MELTED AND REDEPOSITED LAYER (2) RECAST LAYER (3) ANNEALED LAYER

"ON" time no.: 11, "OFF" time no.: 20, IP no.: 17, S: $3(\mathrm{~m} / \mathrm{min}), \mathrm{T}: 5(\mathrm{~N})$, f: 6 (lit. $/ \mathrm{min}), \mathrm{H}: 180(\mu \mathrm{m})$, Wire type: Brass $(63 \% \mathrm{Cu}, 37 \% \mathrm{Zn})$

(a)

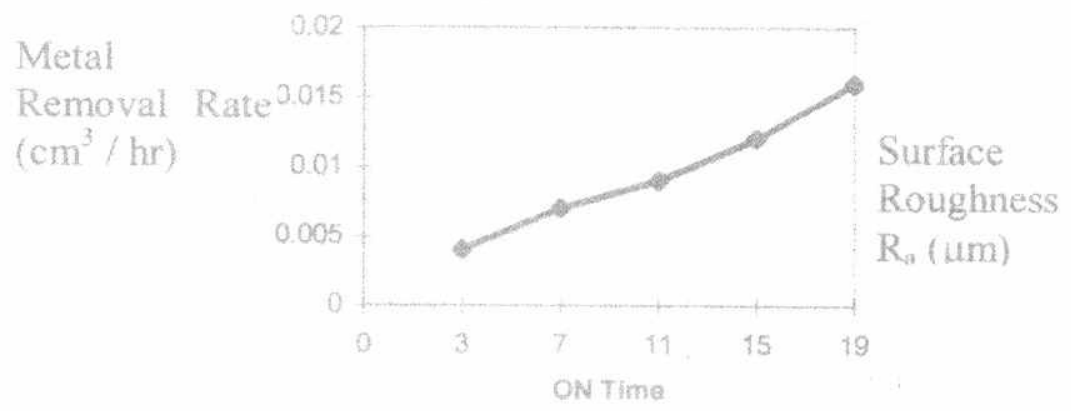

(b)

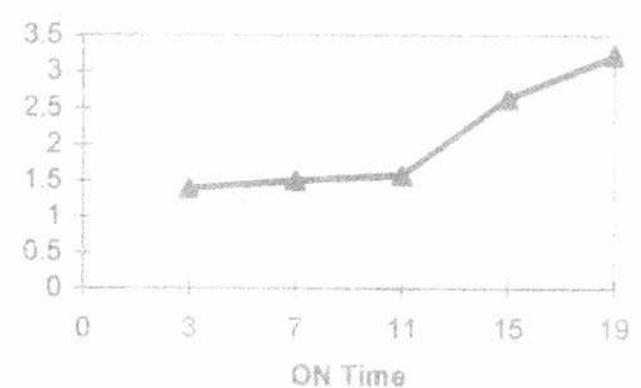

FIG.6: EFFECT OF" "ON "TIME ON:
(a) METAL REMOVAL RATE
(b) SURFACE ROUGHNESS Ra "OFF" time no: 20 , IP: 15, S: 3 (m/min), T: 5 (N), f: 6 (lit / $/ \mathrm{min}), \mathrm{H}: 180(\mu \mathrm{m})$, Wire type: Brass 
(a)

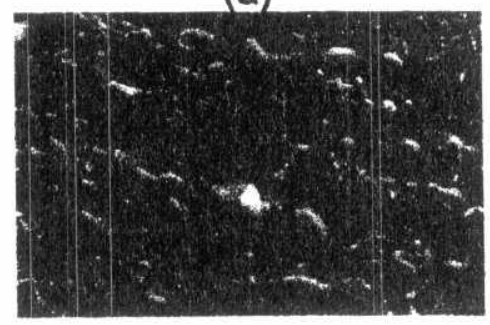

(b)

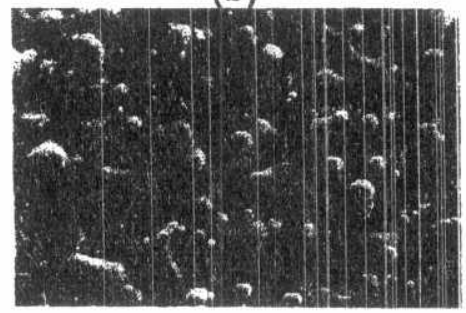

FIG. 7: MIC,ROSTRUCTURE OF THE SURFACE PRODUCED BY WIRE EDM FOR:

(a) ON TIME $=03$

(b) ON TIME $=19$

"OFF" time: 20, IP: 15, S: $3(\mathrm{~m} / \mathrm{min})$, T: $5(\mathrm{~N})$, f: 6 (lit. $/ \mathrm{min}), \mathrm{H}: 180(\mu \mathrm{m})$, Wire type: Brass

(a)

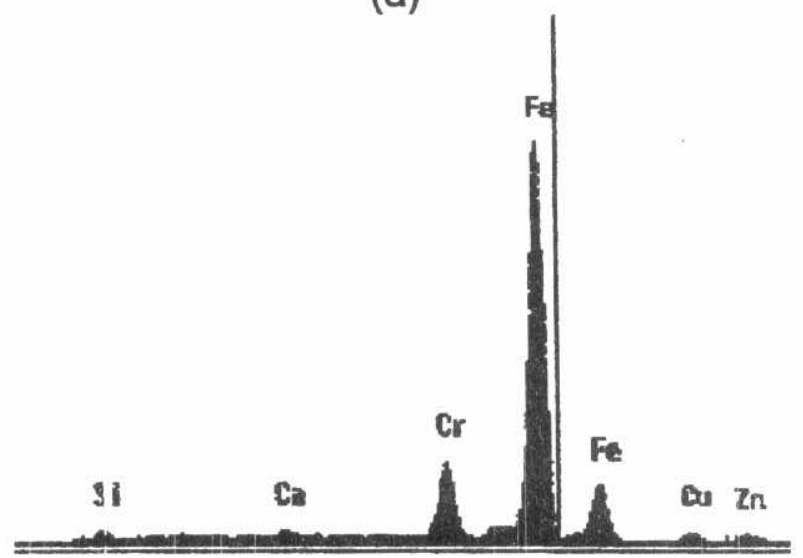

$\mathrm{Cu}: 0.6 \% \mathrm{Zn}: 0.2 \%$ (b)

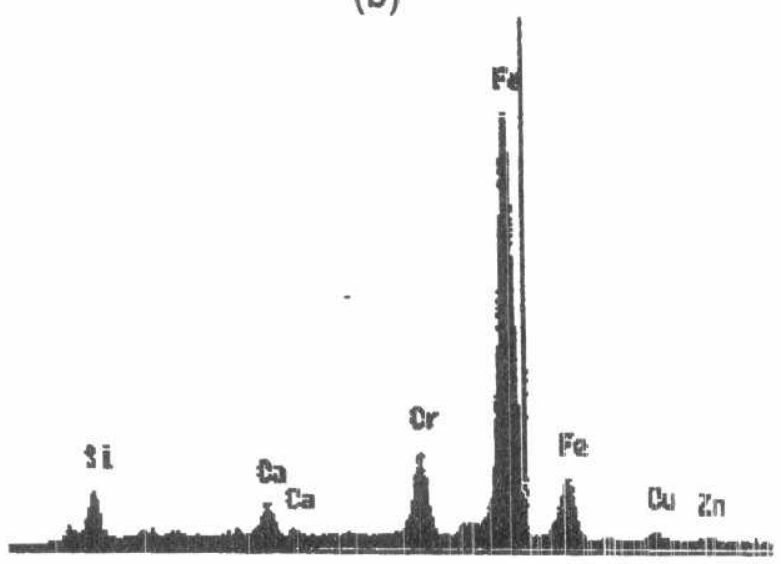

Cu: $3.9 \% \quad \mathrm{Zn}: 1.8 \%$

FIG. 8: EFFECT OF ON TIME ON THE COPPER AND ZINC DEPOSITED ON A SURFACE MACHINED BY WIRE - EDM
(a) ON TIME $=03$
(b) ON TIME $=19$

"OFF" time: 20, IP: 15, S: 3 (m/min), T: 5 (N), f: 6 (lit. /min), H: $180(\mu \mathrm{m})$, Wire type: Brass

(a)

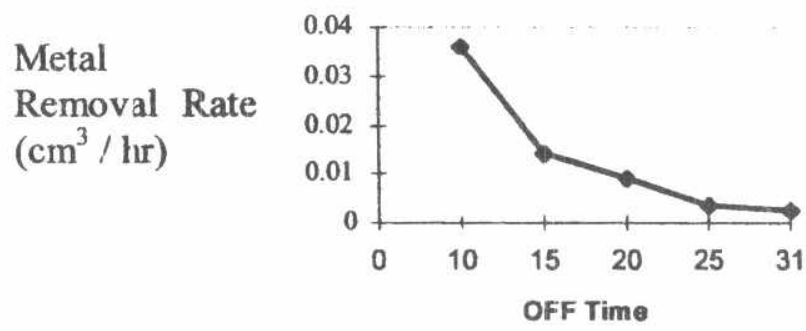

(b)

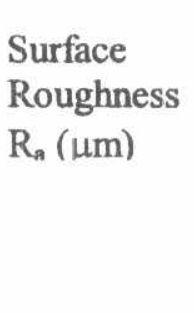

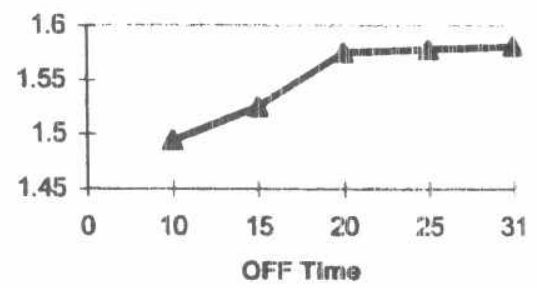

FIG. 9: EFFECT OF OFF TIME ON:

$\begin{array}{ll}\text { (a) METAL REMOVAL RATE } & \text { (b) SURFACE ROUGHNESS } R_{\mathrm{a}}\end{array}$ "ON" time: 11, IP: 15, S: 3 (m/min), T: 5 (N), f: 6 (lit. /min), H: 180 ( $\mu \mathrm{m}$ ) , Wire type: Brass 
High OFF time (Low pulse frequency.), High surface roughness
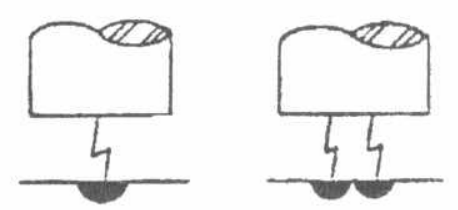

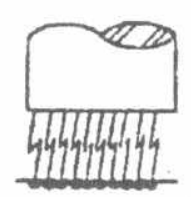

Low OFF time (High pulse frequency.) Low surface roughness

FIG. 10: EFFECT OF SPARK FREQUENCY ON SURFACE FINISH

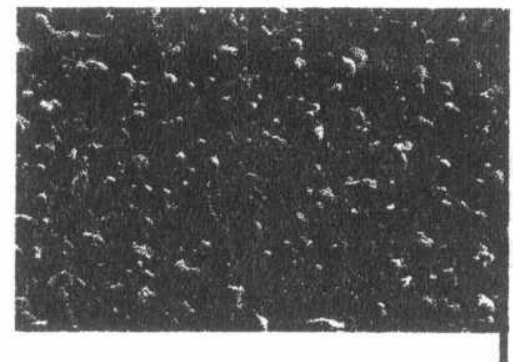

(a)

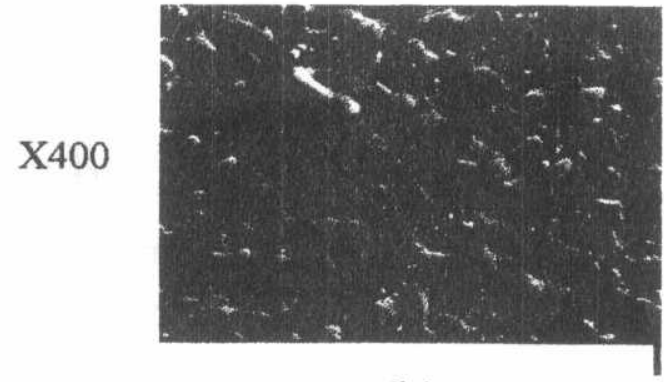

(b)

FIG. 11: MICROSTRUCTURE OF THE SURFACE PRODUCED BY WIRE-EDM FOR: (a) OFF TIME $=10$ (b) OFF TIME $=31$ "ON" time: 11, IP: 15, S: 3 (m/min), T: 5 (N), f: 6 (lit. /min), H: $180(\mu \mathrm{m})$, Wire type: Brass

(a)

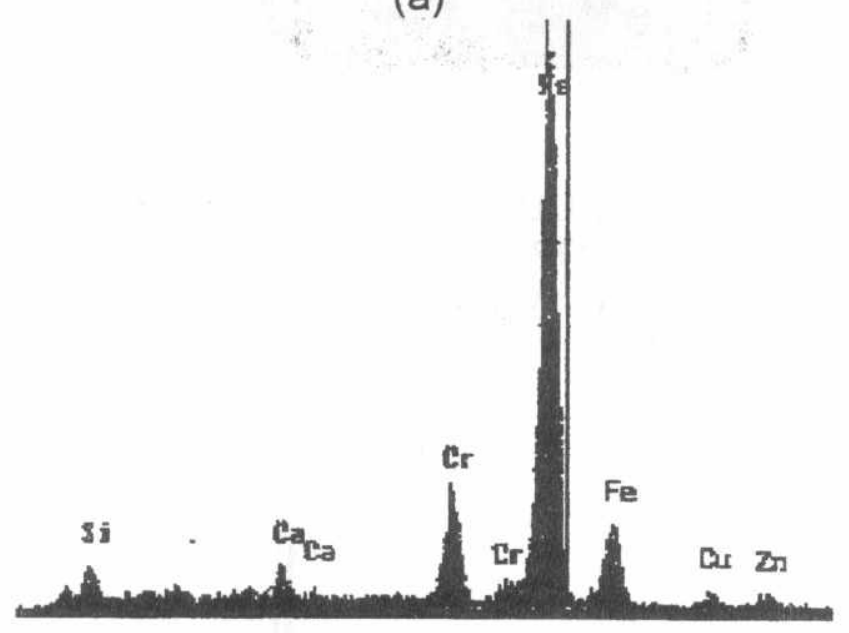

Cu: $1.53 \% \quad Z n: 0.63 \%$ (b)

FIG. 12: EFFECT OF OFF TIME ON THE COPPER AND ZINC DEPOSITED ON A SURFACE MACHINED BY WIRE - EDM
a) OFF TIME $=10$
(b) OFF TIME $=31$

"ON" Time: 11, IP: 15, S: 3 (m/min), T: 5 (N), f: 6 (lit. /min), H: 180 ( $\mu \mathrm{m})$, Wire type: Brass
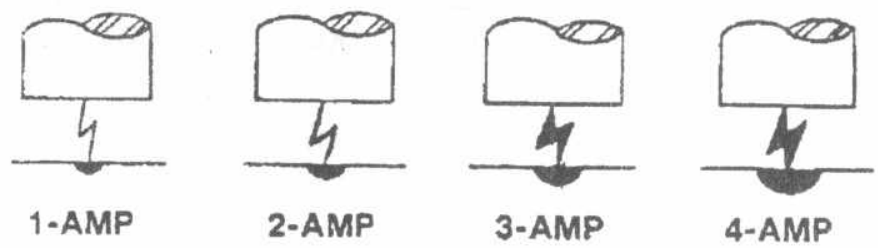

FIG. 13 EFFECT OF CURRENT ON SURFACE FINISH 
(a)

Metal

Removal Rate $\left(\mathrm{cm}^{3} / \mathrm{hr}\right)$

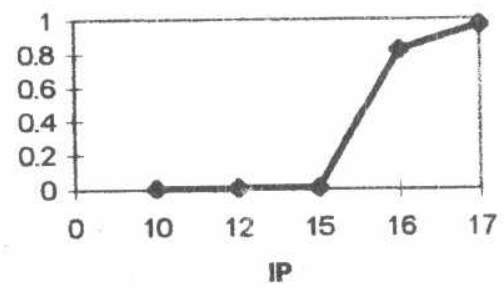

Surface Roughness $\mathrm{R}_{\mathrm{a}}(\mu \mathrm{m})$ (b)

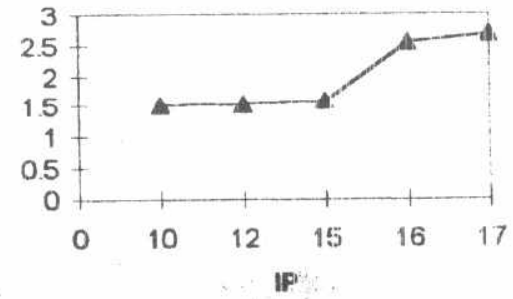

FIG. 14: EFFECT OF CURRENT (IP) ON:

(a) METAL REMOVAL RATE

(b) SURFACE ROUGHNESS Ra)

"ON" time: 11, "OFF" time: 20, S: 3 ( $\mathrm{m} / \mathrm{min})$, T: 5 (N), f: 6 (lit. / $/ \mathrm{min}), H: 180(\mu \mathrm{m})$, Wire Type: Brass

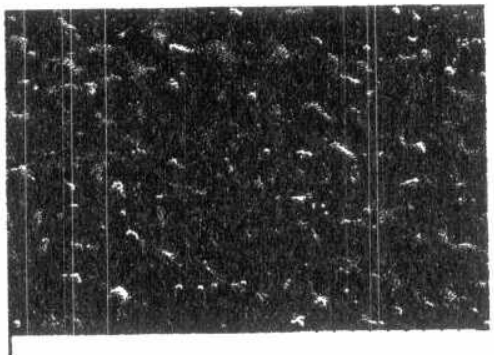

(a)

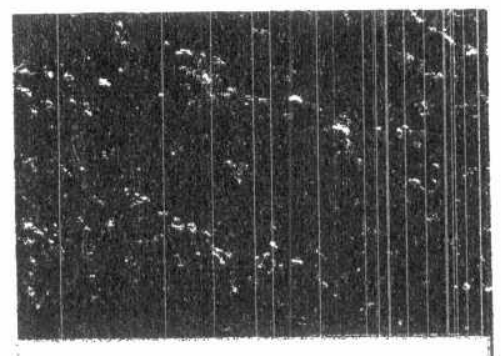

(b)

FIG. 15: MICROSTRUCTURE OF THE SURFACE PRODUCED BY WIRE EDM FOR:

(a) IP $=10$

(b) IP $=17$

"ON" time: 11, "OFF" time: $20, \mathrm{~S}: 3$ (m/min), T: 5 (N), f: 6 (lit. /min) , H: 180 ( $\mu \mathrm{m})$, Wire type: Brass

(a)

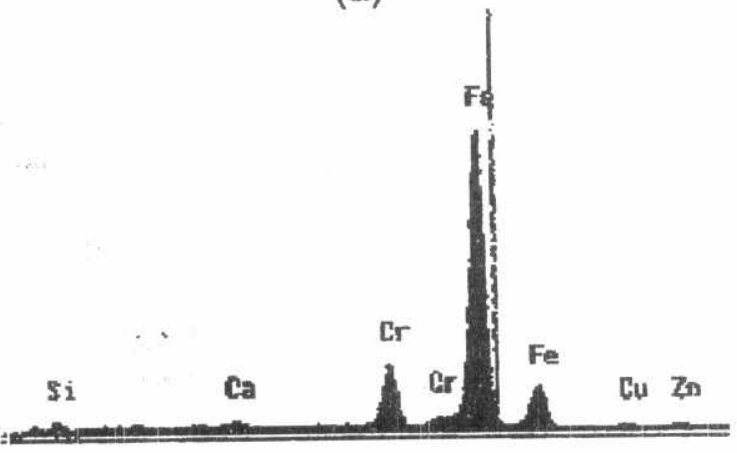

Cu: $0.9 \% \quad \mathrm{Zn:} 0.9 \%$

FIG. 16: EFFECT OF CURRENT (IP) ON THE COPPER AND ZINC

DEPOSITED ON A SURFACE MACHINED BY WIRE - EDM
(a) $I P=15$
(b) IP $=17$

(b)

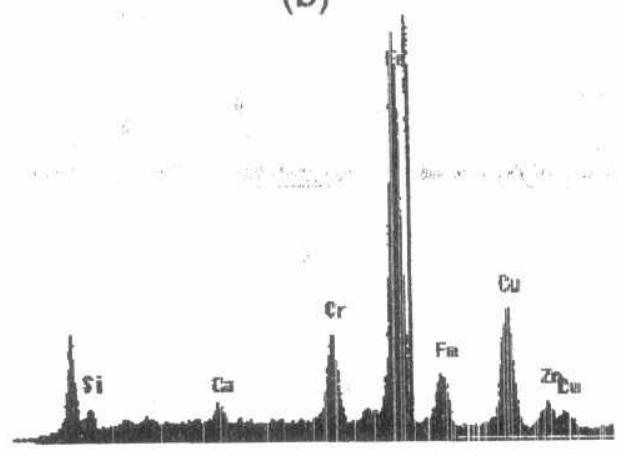

Cu: $26.1 \% \quad Z n: 4.0 \%$

"ON" time: 11, "OFF" time: 20, S: 3 (m/min), T: 5 (N), f: 6 (lit. /min), H: $180(\mu \mathrm{m})$, Wire Type: Brass 
(a)

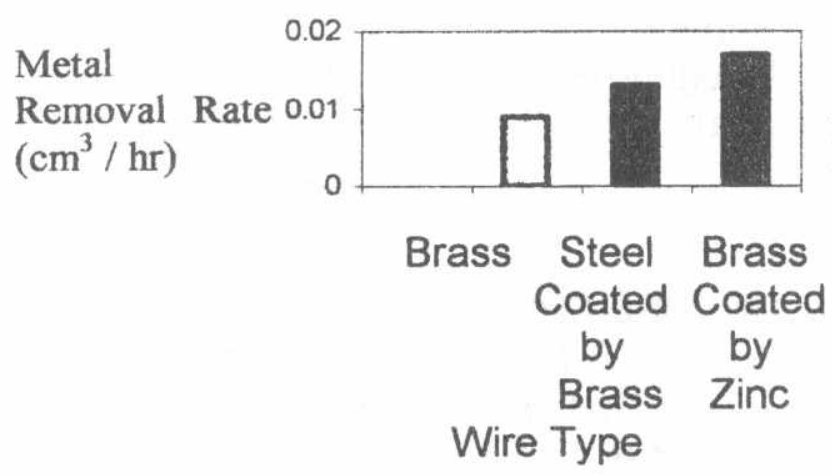

(b)

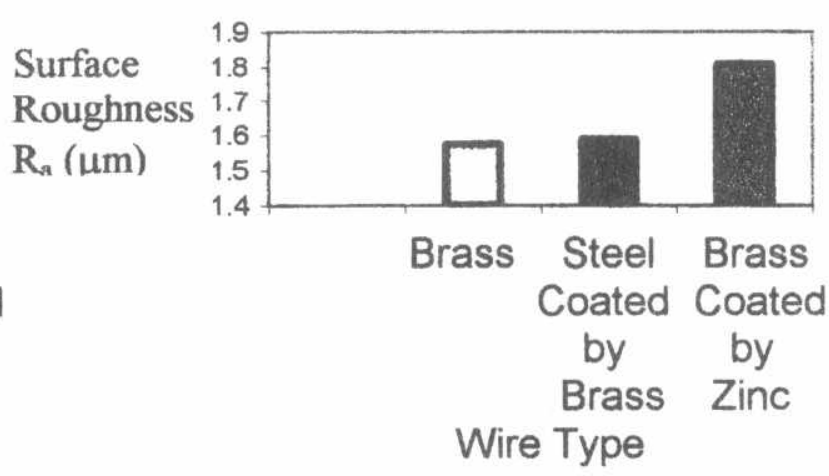

FIG. 17: EFFECT OF WIRE TYPE ON:
(a) Metal Removal Rate
(b) Surface Roughness (Ra)

"ON" time: 11, "OFF" time: 20, IP: 15, S: 3 (m/min), T: 5 (N), f: 6 (lit. /min), H: 180 ( $\mu \mathrm{m}$ )

(a)

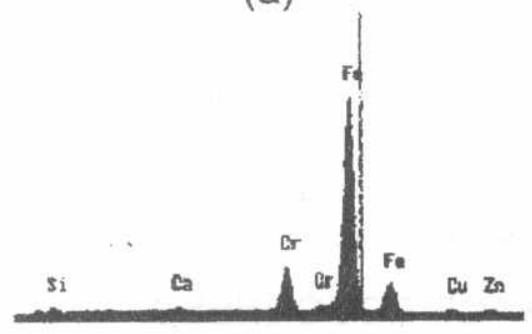

Cu: $0.9 \% \quad \mathrm{Zn}: 0.9 \%$ (b)

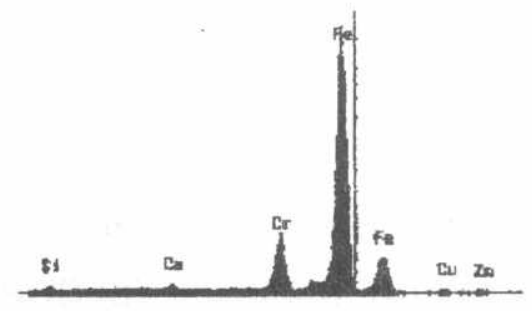

$\mathrm{Cu}: 0.3 \% \quad \mathrm{Zn}: 0.1$ (c)

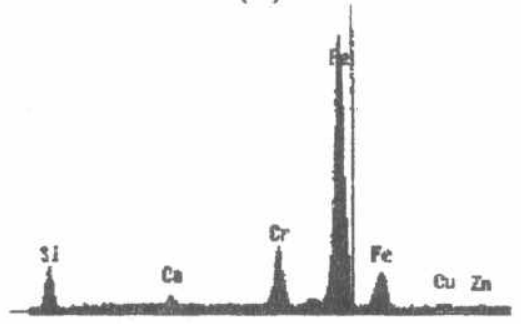

Cu: $0.15 \% \quad \mathrm{Zn}: 0.0 \%$

FIG. 18: EFFECT OF WIRE TYPE ON THE COPPER AND ZINC DEPOSITED ON A SURFACE MACHINED BY WIRE EDM

$\begin{array}{llll}\text { (a) Brass wire } & \text { (b) Steel coated by brass wire } & \text { (c) brass coated by zinc wire }\end{array}$ "ON" time: 11, "OFF" time: 20, IP: 15, S: 3 (m/min), T: 5 (N), f: 6 (lit. /min), H: 180 ( $\mu \mathrm{m}$ )

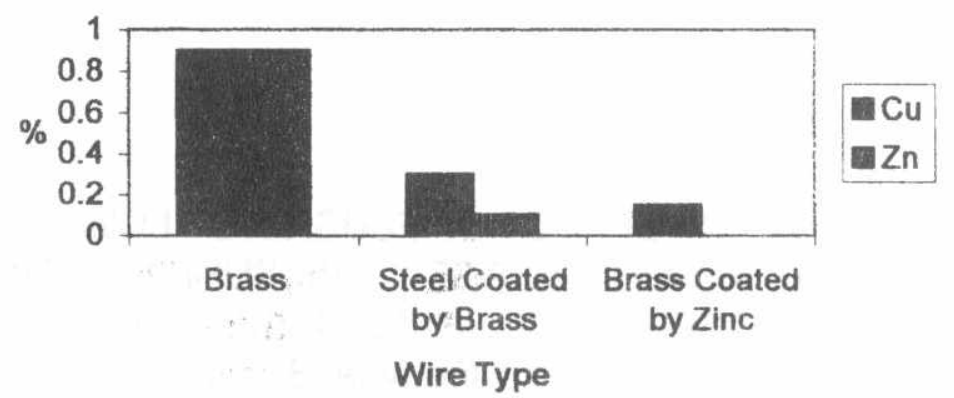

FIG. 19: EFFECT OF WIRE TYPE ON THE COPPER AND ZINC PERCENTAGE DEPOSITED ON A SURFACE MACHINED BY WIRE EDM

"ON" time: 11, "OFF" time: 20, IP: 15, S: 3 (m/min), T: 5 (N), f: 6 (lit. /min), H: 180 ( $\mu \mathrm{m}$ ) 
(a)

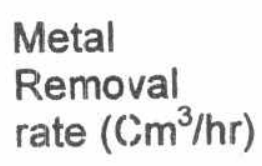

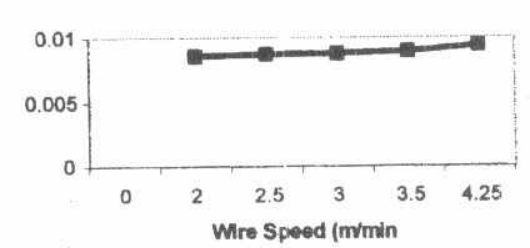

(b)

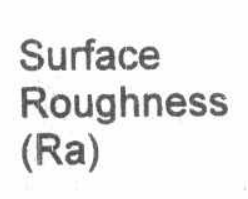

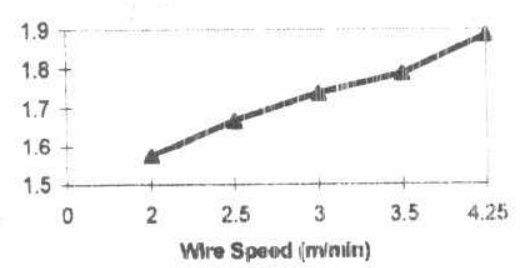

FIG. 20: EFFECT OF WIRE SPEED ON

(a) METAL REMOVAL RATE

(b) SURFACE ROUGHNESS Ra “ON" time: 11, “OFF" time: 20, IP: 15, T: 5 (N), f: 6 (lit. / $/ \mathrm{min}), \mathrm{H}: 180(\mu \mathrm{m})$ Wire type: Brass.

(a)

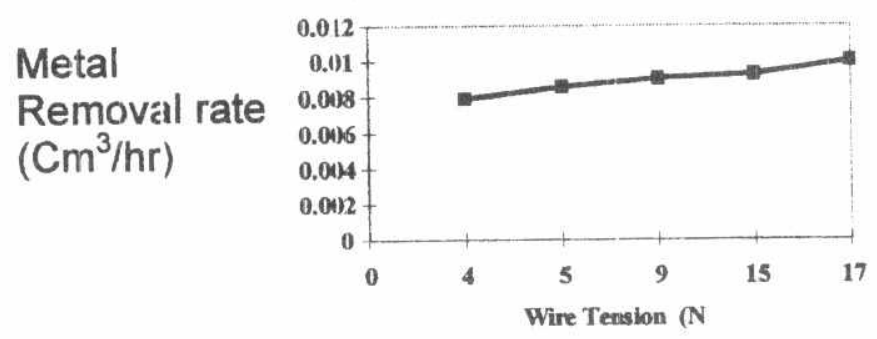

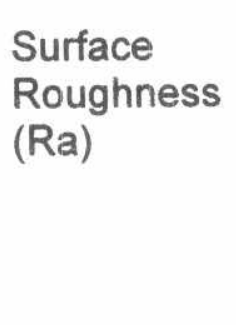

(b)

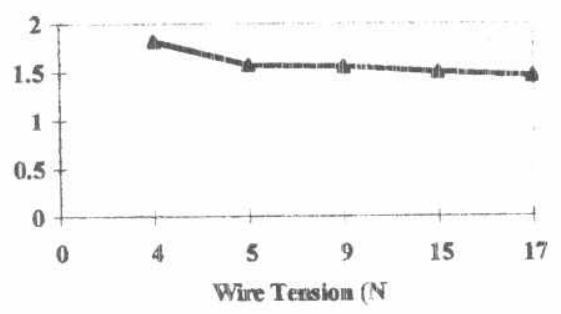

FIG. 21: EFFECT OF WIRE TENSION ON

$\begin{array}{ll}\text { (a) METAL REMOVAL RATE } & \text { (b) SURFACE ROUGHNESS }\end{array}$ "ON" time: 11, "OFF" time: 20, IP: 15, S: 3 (m/min), f: 6 (lit. / $/ \mathrm{min}), \mathrm{H}: 180(\mu \mathrm{m})$ Wire type: Brass.

(a)

Metal

Removial

rate $\left(\mathrm{Cr}^{3} / \mathrm{hr}\right)$

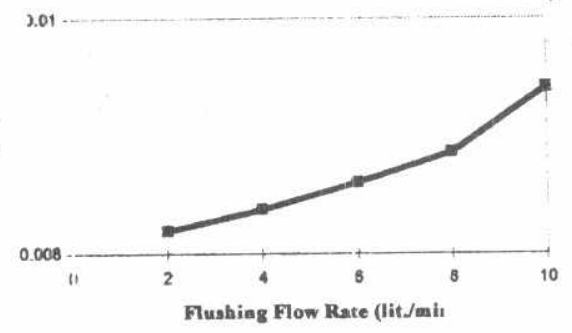

(b)

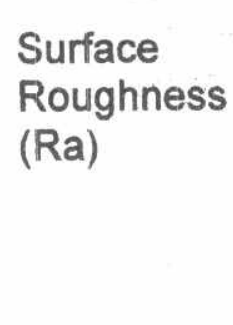

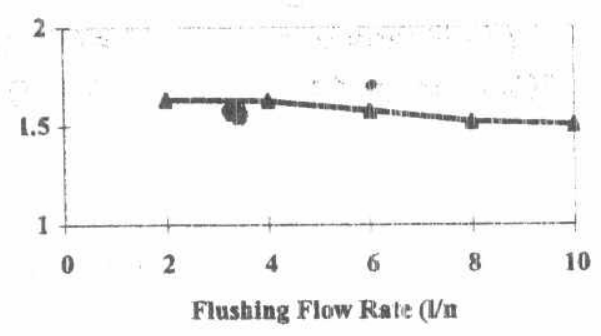

FIG. 22: EFFECT OF FLUSHING FLOW RATE ON

$\begin{array}{ll}\text { (a) METAL REMOVAL RATE } & \text { (b) SURFACE ROUGHNESS Ra }\end{array}$

"ON" time: 11, "OFF" time: 20, IP: 15, S: $3(\mathrm{~m} / \mathrm{min}), \mathrm{T}: 5(\mathrm{~N}), \mathrm{H}: 180(\mu \mathrm{m})$

Wire type: Brass. 